\title{
Conditional ablation of glycogen synthase kinase $3 \beta$ in postnatal mouse kidney
}

\author{
Yan $\mathrm{Ge}^{1,4}$, Jin $\mathrm{Si}^{1,2,4}$, Li Tian ${ }^{1,3,4}$, Shougang Zhuang ${ }^{1}$, Lance D Dworkin ${ }^{1}$ and Rujun Gong ${ }^{1}$
}

Glycogen synthase kinase (GSK)3 is a ubiquitously expressed serine/threonine kinase existing in two isoforms, namely GSK3 $\alpha$ and GSK3 $\beta$. Aside from the long-recognized role in insulin signal transduction and glycogen biosynthesis, GSK3 $\beta$ has been recently coined as a master control molecule in nuclear factor- $\kappa \mathrm{B}$ activation and inflammatory kidney injury. Nevertheless, previous studies are less conclusive because they relied greatly on small molecule inhibitors, which lack selectivity and barely distinguish between the GSK3 isoforms. In addition, early embryonic lethality after global knockout of GSK3 $\beta$ precludes interrogation of the biological role of GSK3 $\beta$ in the adult kidney. To circumvent these issues, the Cre/loxP system was used to generate a conditional knockout mouse model in which the GSK3 $\beta$ gene was specifically deleted in kidney cortical tubules at postnatal mature stage. Kidney-specific ablation of GSK3 $\beta$ resulted in a phenotype no different from control littermates. Knockout mice (KO) were viable and exhibited normal development and normal kidney physiology in terms of kidney function, urine albumin excretion, and urine-concentrating ability. It is noteworthy that apart from normal glomerular and tubulointerstitial morphology, the kidneys from KO demonstrated more glycogen accumulation in the renal cortical tubules as assessed by both periodic acid-Schiff staining for light microscopy and direct biochemical assay, consistent with an elevated glycogen synthetic activity as evidenced by diminished inhibitory phosphorylation of glycogen synthase that occurred subsequent to GSK3 $\beta$ ablation. This finding was further validated by electron microscopic observations of increased deposition of glycogen particles in the renal tubules of KO, suggesting that GSK3 $\alpha$ could not fully compensate for the loss of GSK3 $\beta$ in regulating glycogen metabolism in the kidney. Collectively, our study suggests that kidney-specific ablation of GSK3 $\beta$ barely affects kidney function and histology under normal circumstances. Extended examinations of these KO under diseased conditions are merited to understand the role of GSK3 $\beta$ in renal pathophysiology.

Laboratory Investigation (2011) 91, 85-96; doi:10.1038/labinvest.2010.142; published online 2 August 2010

KEYWORDS: conditional knockout; glomerulus; glycogen; glycogen synthase kinase $3 \beta$; kidney; mouse; tubule

Glycogen synthase kinase (GSK)3 is a well-conserved, ubiquitously expressed, and constitutively active serine/ threonine protein kinase, which was originally identified as one that mediates inhibitory phosphorylation of glycogen synthase and either inactivates glycogen synthase or activates ATP-Mg-type 1 protein phosphatase. ${ }^{1-4}$ Interest in GSK3 expanded greatly with the realization that it is a key regulator of cell processes extending well beyond glycogen metabolism to signal transduction, insulin action, gene transcription, protein synthesis, cytoskeletal organization, cell-cycle progression, and development control. ${ }^{1,3,5}$
In mammalian cells, GSK3 exists as two isoforms, GSK3 $\alpha$ $(51 \mathrm{kDa})$ and GSK3 $\beta(47 \mathrm{kDa})$, which are encoded by separate genes that produce highly homologous proteins that differ significantly only in their $\mathrm{N}$ - and C-terminal regions. ${ }^{1}$ Although displaying $84 \%$ structural homology, GSK3 $\alpha$ and GSK $3 \beta$ are not functionally interchangeable, and GSK3 $\beta$ possesses unique biological actions. ${ }^{5-9}$ In support of this, mice engineered to lack GSK3 $\beta$ (but still retaining GSK3 $\alpha$ ) die at mid-gestation because of severe liver degeneration, suggesting that GSK3 $\alpha$ and GSK3 $\beta$ have distinct biological roles, as the former is unable to compensate for the loss of

\footnotetext{
${ }^{1}$ Department of Medicine, Brown University School of Medicine, Providence, Rhode Island, USA; ${ }^{2}$ Department of Laboratory Medicine, The Second Affiliated Hospital, Nanjing Medical University, Nanjing, China and ${ }^{3}$ Department of Medical Technology, The Third Affiliated Hospital, Henan University of Chinese Traditional Medicine, Zhengzhou, China

Correspondence: Dr R Gong, MD, PhD, Division of Kidney Diseases and Hypertension, Department of Medicine, Brown Medical School, 593 Eddy Street, Providence, RI 02903, USA.

${ }^{4}$ These authors contributed equally to this work.

Received 25 March 2010; revised 28 May 2010; accepted 27 June 2010
} 
the latter. ${ }^{10}$ In-depth study showed that GSK3 $\beta$ function is required for the nuclear factor $(\mathrm{NF}) \kappa \mathrm{B}$-mediated anti-apoptotic response to tumor necrosis factor. ${ }^{10-12}$ Consistently, recent data have demonstrated that GSK3 $\beta$ is a key regulator of $\mathrm{NF} \kappa \mathrm{B}$ activity. ${ }^{11,13-15}$ GSK3 $\beta$ directly binds and phosphorylates $\mathrm{NF} \kappa \mathrm{B}$, thereby promoting the transactivation of multiple proinflammatory mediators, including chemokines and adhesion molecules. ${ }^{16,17}$ In patients with inflammatory renal disease, GSK $3 \beta$ was found to be associated with the extent of $\mathrm{NF} \kappa \mathrm{B}$ activation and the magnitude of inflammatory injury in the diseased kidney. ${ }^{16}$ Moreover, selective inhibitors of GSK3 $\beta$ have been lately found to protect from acute kidney injury in animal models. ${ }^{18-23}$

Although GSK3 $\beta$ has been coined as a master control molecule in $\mathrm{NF} \kappa \mathrm{B}$ activation and inflammatory injury, ${ }^{10,11,13-15,17,24}$ most of the previous findings were based on small molecule inhibitors of GSK3, which are unable to discriminate between GSK $3 \alpha$ and GSK $3 \beta ; ;^{19,20,25}$ thus, it is not possible to precisely evaluate the role of GSK $3 \beta$ in the pathogenesis of renal inflammation using these drugs. Genetic disruption of GSK3 $\beta$ would be more selective; however, mice with global GSK3 $\beta$ knockout die in embryo stages because of massive hepatic necrosis. ${ }^{10}$ Therefore, to circumvent this early embryonic lethality, it is imperative to establish a mouse model in which the kidney-specific expression of $G S K 3 \beta$ is specifically deleted. Moreover, considering that GSK3 $\beta$ and its related signaling pathways are indispensable for embryonic kidney development, ${ }^{26}$ kidneyspecific ablation of GSK3 $\beta$ at postnatal stage will be an ideal approach to avoid potential congenital defects of the kidney.

In this study, we used the Cre/loxP gene targeting system ${ }^{27}$ and generated conditional knockout mice (KO) in which the GSK3 $\beta$ gene was specifically disrupted in the kidney cortical tubular epithelium at postnatal maturity stage. Mice with kidney-specific knockout of GSK3 $\beta$ are generally healthy with normal kidney physiology and histology, except evident glycogen accumulation in tubular epithelial cells as compared with control littermates. This novel transgenic mouse model might serve as an invaluable tool to understand the role of GSK3 $\beta$ in kidney physiology and pathology.

\section{MATERIALS AND METHODS Generation of Kidney Tubular-Specific GSK3 $\beta$ KO and Genotyping}

Animal experimental studies were approved by the institution's Animal Care and Use Committee and they conform to the USDA regulations and the NIH guidelines for humane care and use of laboratory animals. Mice (C57BL/6J strain) with the floxed GSK3 $\beta$ gene were obtained from Dr James Woodgett (Samuel Lunenfeld Research Institute of Mount Sinai Hospital, Toronto, Canada). ${ }^{8}$ These mice carry two loxp loci flanking exon 2, allowing excision of exon 2 and disruption of the GSK3 $\beta$ gene in the presence of Cre recombinase. These 'floxed' mice appear phenotypically identical to wild-type mice with normal physiological and functional activities. Transgenic mice expressing Cre recombinase under the control of a $\gamma$-glutamyltranspeptidase $(\gamma G T)$ promoter were obtained from Dr Eric Neilson (Venderbilt University, Nashville, TN, USA). ${ }^{28}$ By mating GSK3 $\beta$-floxed mice with $\gamma$ GT.Cre transgenic mice, mice that were heterozygous for the GSK3 $\beta$-floxed allele were generated (genotype: GSK3 $\beta^{\mathrm{fl} /+}$, Cre). These mice were crossbred to generate the desired knockout offspring that were homozygous for the GSK3 $\beta$-floxed allele and carried the Cre allele (genotype: GSK $3 \beta^{\mathrm{fl} / \mathrm{fl}}$, Cre). The breeding protocol also generated heterozygous littermates (genotype: GSK3 $\beta^{\mathrm{fl} /+}$, Cre) as well as wild-type and several control groups (Ctrl) with different genotypes $\left(\mathrm{GSK} 3 \beta^{+/+}\right.$; GSK3 $\beta^{\mathrm{fl} / \mathrm{fl}} ; \mathrm{GSK} 3 \beta^{\mathrm{fl} /+}$; GSK3 $\beta^{+/+}$, Cre; referred to as controls). A routine PCR protocol was used for genotyping tail DNA samples with the following primer pairs: $\gamma$ GT.Cre genotyping, forward: $5^{\prime}$-AGGTGTAG AGAAGGCACTTAGC- $3^{\prime}$ and reverse: $5^{\prime}$-CTAATCGCCATCT TCCAGCAGG-3', which generated a 411-bp fragment; and GSK3 $\beta$ genotyping, forward: 5'-GGGGCAACCTTAATTT CATT- $3^{\prime}$ and reverse: $5^{\prime}$-GTGTCTGTATAACTGACTTCCTG TGGC-3' ${ }^{\prime}$, which yielded 685- and 585-bp bands, respectively, for the floxed and wild-type alleles. An alternative sequence of the reverse primer: $5^{\prime}$-TCTGGGCTATAGCTATCTAGTA ACG- $3^{\prime}$ was used to genotype solid organs, such as the heart, liver, and kidney, and yielded 1095, 886, and 209 bp bands, respectively, for the floxed, wild-type, and excised alleles. Transgenic mice were born normally at the expected Mendelian distribution. In all experiments, littermates from the same breeding pairs were used as controls.

\section{Blood Pressure Measurement}

Just before death, mice were anesthetized and prepared for a measurement of mean arterial pressure (MAP). A polyethylene catheter was inserted into the femoral artery. After a 15-min equilibration period, a computer running WINDAS software (DATAQ Instruments, Akron, OH, USA) continuously monitored and documented the steady mean arterial blood pressure using a pressure transducer.

\section{RNA Extraction and Real-Time Reverse Transcription-PCR}

Total RNA was extracted from indicated animal tissues using TRIzol solution (Invitrogen, Carlsbad, CA, USA) according to the instructions specified by the manufacturer. RNA was then diluted to $3 \mu \mathrm{g} / \mu \mathrm{l}$ in RNase-free distilled water. Firststrand cDNA was prepared using $3 \mu \mathrm{g}$ RNA, Superscript RT reverse transcriptase (Invitrogen), and oligo (dT) primer according to the manufacturer's instructions. Quantitative real-time PCR was carried out on a Stratagene Mx4000 multiplex quantitative PCR system (Stratagene, La Jolla, CA, USA) using primers specific for murine $G S K 3 \beta$, forward: $5^{\prime}$-GGCAGCAAGGTAACCACAGT- $3^{\prime}$ and reverse: $5^{\prime}$-GATGG CAACCAGTTCTCCAG-3' ${ }^{\prime}$, and for murine glyceraldehyde 3-phosphate dehydrogenase (GAPDH), forward: 5'-CGAGAT CCCTCCAAAATCAA- $3^{\prime}$ and reverse: 5'-TTCACACCCAT 
GACGAACAT-3'. All reactions were performed in triplicate using Brilliant SYBR Green QPCR Master Mix (Stratagene). Fluorescence values of SYBR Green I dye, representing the amount of product amplified at that point in the reaction, were recorded in real time at both the annealing step and the extension step of each cycle. The $C_{t}$ value, defined as the point at which the fluorescence signal was statistically significant above background, was calculated for each amplicon in each experimental sample using the Stratagene Mx4000 software. This value was then used to determine the relative amount of amplification in each sample by interpolating from the standard curve. The transcript level of GSK3 $\beta$ was normalized to GAPDH amplification.

\section{SDS-PAGE and Western Immunoblot Analysis}

Animal tissues were homogenized in RIPA buffer supplemented with protease inhibitors (1\% Nonidet P- $40,0.1 \%$ SDS, $100 \mu \mathrm{g} / \mathrm{ml}$ phenylmethysulfonyl fluoride, $0.5 \%$ sodium deoxycholate, $1 \mathrm{mM}$ sodium orthovanadate, $2 \mu \mathrm{g} / \mathrm{ml}$ aprotin, $2 \mu \mathrm{g} / \mathrm{ml}$ leupeptin, $5 \mathrm{mM}$ EDTA in PBS). Protein concentration was determined using a bicinchoninic acid protein assay kit (Sigma, St Louis, MO, USA). Samples with equal amounts of total protein $(50 \mu \mathrm{g})$ were fractionated by $7.5-15 \%$ SDSpolyacrylamide gels under reducing conditions and analyzed by western immunoblot as described previously. ${ }^{29}$ The polycolonal antibodies against actin, GSK3 $\beta$, WT1, and podocin was purchased from Santa Cruz Biotechnology (Santa Cruz, CA, USA) and those for nephrin were acquired from Progen (Heidelberg, Germany). The monocolonal antibody against GSK3 $\beta$ was purchased from Cell Signaling Technology (Beverly, MA, USA). To discern the protein compositions of urine, equal amount of urine samples were subjected to SDS-PAGE, followed by Coomassie blue staining.

\section{Biochemical Analysis of Urine and Serum}

Urine albumin was measured using a mouse Albumin ELISA quantitation kit, according to the manufacturer's protocol (Bethyl Laboratories, Montgomery, TX, USA). Serum and urine creatinine and blood urea nitrogen (BUN) were determined by a routine procedure as described previously. ${ }^{30}$

\section{Glomerular Isolation}

Glomerular isolation was carried out according to the method described elsewhere. ${ }^{31}$ In brief, mice were anesthetized and perfused by infusing the abdominal artery with $5 \mathrm{ml}$ of PBS containing $8 \times 10^{7}$ Dynabeads M-450 (Dynal Biotech ASA, Oslo, Norway). After perfusion, the kidneys were removed and cut into $1-\mathrm{mm}^{3}$ pieces and digested in collagenase $\mathrm{A}(1 \mathrm{mg} / \mathrm{ml})$ at $37^{\circ} \mathrm{C}$ for $30 \mathrm{~min}$ with gentle shaking. The tissue was then pressed gently through a $100-\mu \mathrm{m}$ cell strainer (BD Falcon, Bedford, MA, USA). The glomeruli containing Dynabeads were then gathered using a magnetic particle concentrator. The isolated glomeruli were washed three times with cold PBS and used for subsequent studies.

\section{Morphological Studies}

Formalin-fixed kidneys were embedded in paraffin and prepared in $3 \mu \mathrm{m}$-thick sections. For general histology, sections were processed for hematoxylin and eosin (H\&E) staining and periodic acid-Schiff (PAS) staining. Morphology of all sections was assessed by a single observer in a blinded manner.

\section{Immunofluorescent staining}

Indirect immunofluorescent staining of GSK3 $\beta$ was carried out on frozen kidney sections using rabbit monoclonal anti-GSK3 $\beta$ antibody (Cell Signaling Technology). The Alexa Fluor goat anti-rabbit IgG (Molecular Probes, Eugene, OR, USA) was used as secondary antibody. As a negative control, the primary antibody was replaced by nonimmune serum from the same species; no staining occurred. Immunofluorescent staining of podocin, nephrin, and WT1 was performed in a similar manner using respective antibodies. For fluorescence microscopy, all sections were stained and analyzed at the same time to exclude artifacts due to variable decay of the fluorochrome. ${ }^{29}$ Sections were examined using a Nikon Microphot-FX fluorescence microscope equipped with a Spot II digital camera.

\section{Computerized morphometry}

Fluorescent immunohistochemistry images were captured and digitized using a computerized image analysis system consisting of a high-resolution charge-coupled device digital camera attached to a fluorescent microscope (Olympus BX41, Japan) and to a computer. Images were displayed at a pixel resolution of $1024 \times 768$ pixels (spatial resolution $=0.11 \mu \mathrm{m}$ per pixel). The Image Pro Plus version 5.1 software (MediaCybernetics, MD, USA) was used for image segmentation, threshold establishment, and signal intensity measurements. Manual corrections were performed as required. Overall, 40 glomeruli were sampled for morphometric analysis and final data were expressed as the value of integrated pixel density relative to the control group.

\section{Transmission electron microscopy}

For transmission electron microscopy, the kidney was cut into small pieces $\left(<1 \mathrm{~mm}^{2}\right)$, fixed with $2.5 \%$ glutaraldehyde in $0.1 \mathrm{M}$ sodium cacodylate buffer, $\mathrm{pH} 7.4$, postfixed with $1 \%$ (wt/vol) osmium tetroxide, and embedded in Epon 812 (Polysciences, Warrington, PA, USA). Conventional electron micrographs were obtained using a Zeiss EM-10 microscope operated at $60 \mathrm{kV}$ and absolute magnifications of 63000 or 80000 . Absolute counting of total measurable glycogen particles was performed in 10 random electron microscopy fields of tubules per mouse in 6 mice per group. 


\section{Determination of Glycogen Content}

Kidney tissues were collected, cut, weighed, and made soluble by boiling for $30 \mathrm{~min}$ in $30 \%$ potassium hydroxide saturated with sodium sulfate. Once tissues were completely digested, glycogen was precipitated with $95 \%$ ice-cold ethanol and incubated on ice for $20 \mathrm{~min}$. Samples were spun for $30 \mathrm{~min}$ at $500 \mathrm{~g}$. The pellets were resuspended in $1 \mathrm{ml}$ distilled water and $1 \mathrm{ml} \mathrm{5 \%}$ phenol was added. A colorimetric reaction was obtained by adding $5 \mathrm{ml}$ of sulfuric acid. After incubation on ice for $30 \mathrm{~min}$, absorbance was determined at a wavelength of $490 \mathrm{~nm}$. Contents of glycogen in tissue samples were determined from glycogen standards (Sigma) run with each assay and normalized to tissue weight of each individual sample. Final results were expressed as microgram of collagen per milligram of kidney. Glycogen was also visualized in paraffin-embedded tissue sections by PAS staining for light microscopy.

\section{Statistics}

For immunoblot analysis, bands were scanned and the integrated pixel density was determined using a densitometer and the National Institutes of Health image analysis program. All data are expressed as mean \pm s.d. Statistical analysis of the data from multiple groups was performed by ANOVA, followed by Student-Newman-Keuls tests. Data from two groups were compared by $t$-test. $P<0.05$ was considered significant.

\section{RESULTS}

\section{Breeding Strategy to Target the GSK3 $\beta$ Gene in the Kidney}

Using the Cre/loxP-mediated recombination strategy (Figure 1a), a conditional knockout mouse model, in which the GSK $3 \beta$ gene was specifically deleted in renal tubular epithelial cells was created on the C57BL/6 background. The structure of the loxP-flanked (floxed) GSK3 $\beta$ allele is shown in Figure 1a. LoxP sites were inserted to flank exon 2 at the GSK3 $\beta$ locus through homologous recombination in embryonic stem cells, as described previously. By crossing GSK3 $\beta$-floxed mice with $\gamma$ GT.Cre transgenic mice in which Cre recombinase was driven under the $\gamma G T$ promoter, mice heterozygous for the GSK3 $\beta$-floxed allele were generated (genotype: GSK3 $\beta^{\mathrm{fl} /+}$, Cre) (Figure $1 \mathrm{~b}$ ). These mice were further crossbred to inactivate both GSK3 $\beta$ alleles by Cremediated excision, thereby creating conditional $\mathrm{KO}$ in which the GSK3 $\beta$ gene was specifically disrupted in the kidney cortical tubular epithelium (genotype: GSK3 $\beta^{\mathrm{fl} / \mathrm{fl}}$, Cre). The breeding protocol also generated heterozygous littermates (genotype: GSK3 $\beta^{\mathrm{fl} /+}$, Cre) as well as wild-type and several control groups (Ctrl) with different genotype $\left(\mathrm{GSK} 3 \beta^{+/+}\right.$;

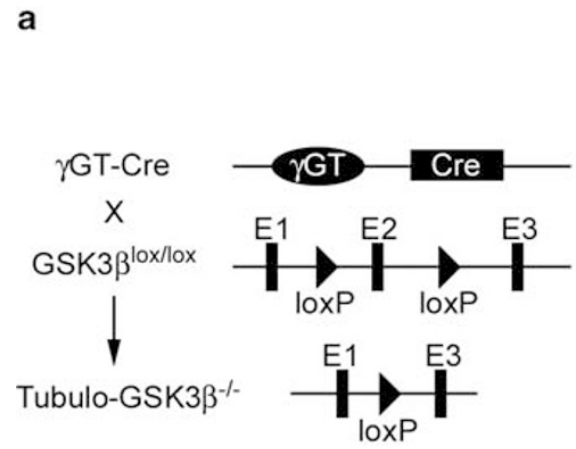

b

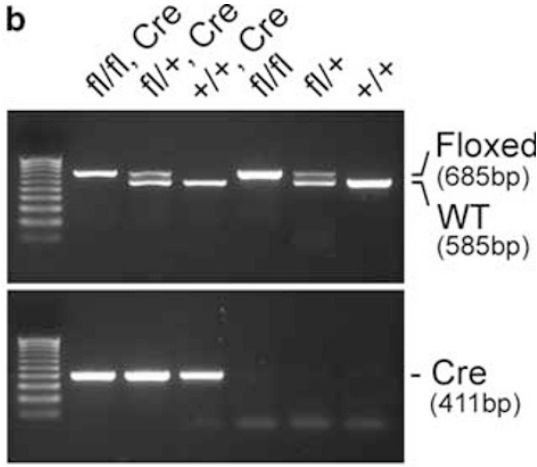

C

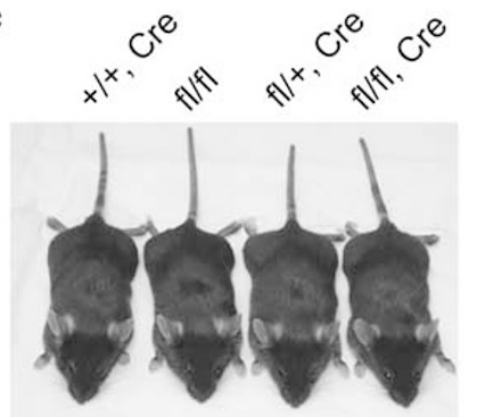

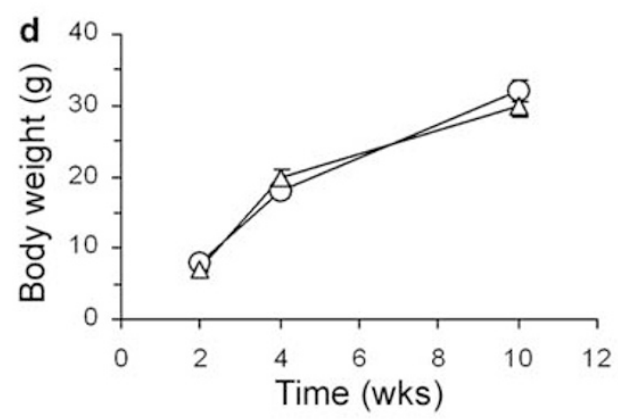

Figure 1 Breeding strategy to target the GSK3 $\beta$ gene in the kidney. (a) Schematic diagram depicts the strategy of generating tubular epithelial cell-specific GSK3 $\beta$ gene knockout mice. The deletion of exon 2 (E2) in the event of recombination of the GSK3 $\beta$ gene is shown; arrowheads: loxP sites. (b) Representative photos showing PCR analysis of the genomic DNA extracted from the clipped tail tissues. The PCR bands of wild-type (585 bp), floxed (685 bp) GSK3 $\beta$, and Cre (411 bp) are indicated. Genotypes of representative litters are indicated; fl, GSK3 $\beta$ floxed. (c) Representative photos showing that mice with different genotypes were viable with no notable difference in gross appearance, development, and behavior. (d) Body weight curve from a representative litter of sex-matched (male) knockout mice (open circle) and control littermates (open triangle); KO versus Ctrl not significant ( $n=6$ ). 
GSK3 $\beta^{\mathrm{fl} / f \mathrm{l}} ; \mathrm{GSK} 3 \beta^{\mathrm{fl} /+}$; GSK3 $\beta^{+/+}$, Cre) (Figure $1 \mathrm{~b}$ ). These mice were viable and fertile with no notable difference in gross appearance (Figure 1c), behavior, body weight (Figure 1d), and development.

\section{Kidney-Specific Ablation of the GSK3 $\beta$ Gene at Postnatal Mature Stage}

The gross appearance (Figure 2a) and weight (Figure 2b) of the kidney from $\mathrm{KO}$ were also normal as compared with that from control littermates. To examine the efficiency and specificity of GSK3 $\beta$ conditional knockout, message RNA expression levels of GSK3 $\beta$ were evaluated by quantitative real-time reverse transcriptase (RT)-PCR analysis on RNA extracted from different tissues from $\mathrm{KO}$ and control mice. The expression of GSK3 $\beta$ mRNA was barely affected in any other extrarenal organs, including the liver, heart, and skeletal muscle, but significantly diminished in the KO kidney to $\sim 30 \%$ of the level in the control kidney (Figure $2 \mathrm{c}$ ). Next, to confirm the specificity of recombination of the GSK3 $\beta$-floxed allele mediated by Cre excision, PCR analysis was carried out on genomic DNA extracted from the kidney and extrarenal organs. As shown in Figure 2d, the excised GSK3 $\beta$ allele was evidently detected (209-bp band) only in the kidney from KO mice, but not in the kidney from control littermates. In addition, excision of the floxed GSK3 $\beta$ allele only occurred in the kidney, but not in other tissues, such as the heart, skeletal muscle, or liver (data not shown) from KO mice. No tissues from control littermates exhibited a Cre-mediated recombination. It is noteworthy that in PCR amplicons derived from the kidney of KO mice, a very faint 1095-bp band corresponding to the floxed GSK3 $\beta$ allele was still observable (Figure $2 \mathrm{~d}$ ), suggesting that the GSK3 $\beta$ gene in very few renal cells was not ablated. Considering the fact that tubular epithelial cells account for a major part of kidney mass, this residual signal could be ascribed to the intact GSK3 $\beta$ gene in nontubular kidney cells, including mesangial cells, podocytes, vascular cells, and other resident kidney cells, in which the $\gamma G T$ promoter remains inactive. ${ }^{28}$ a

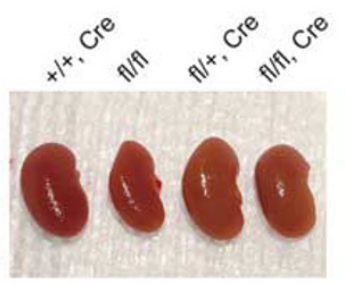

d

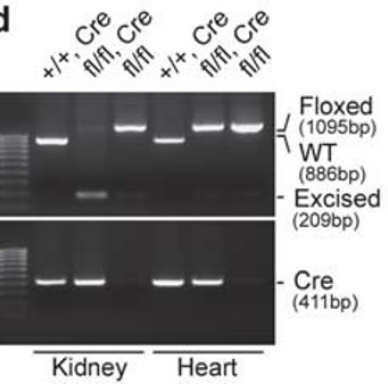

b

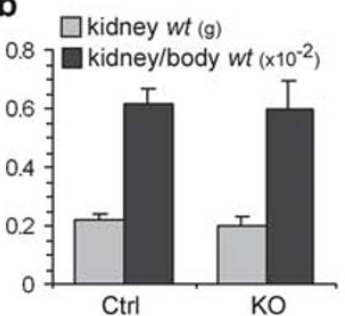

e

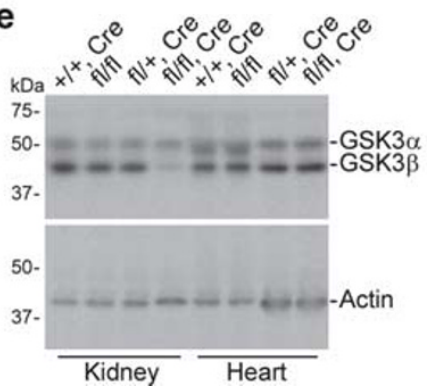

c

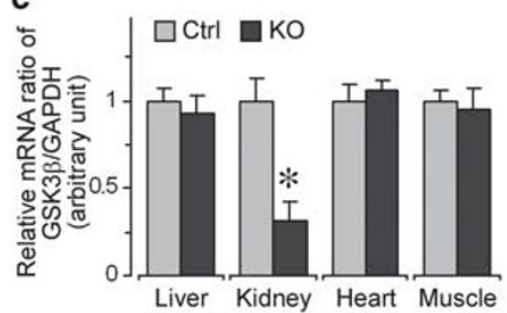

f

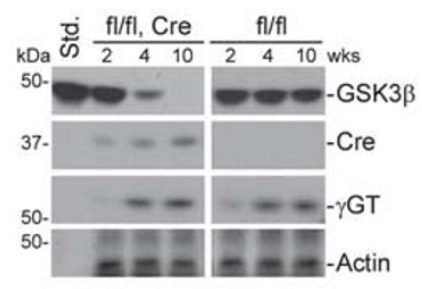

g
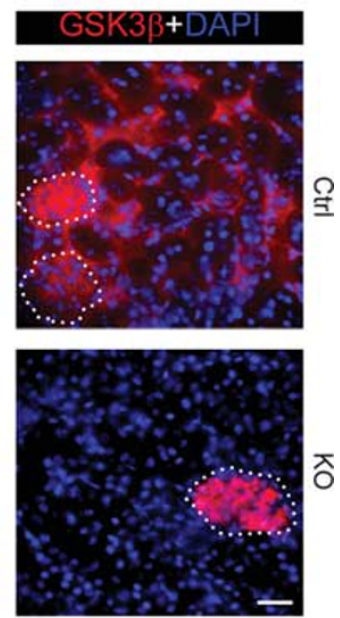

Figure 2 Successful ablation of the GSK3 $\beta$ gene in renal tubules in the postnatal kidney without inducing notable abnormality in gross appearance. (a) A representative litter of sex-matched (male) mice of the indicated genotypes had normal and similar kidneys in terms of gross appearance, size, and color. (b) Knockout (KO) mice and Control (Ctrl) littermates had similar and normal kidney weight and kidney to body weight ratio; KO versus Ctrl not significant $(n=6)$. (c) RNA was extracted from indicated organs from KO and Ctrl mice. Message RNA expression levels of GSK3 $\beta$ in different organs were evaluated by quantitative real-time RT-PCR analysis, normalized to GAPDH amplification, and expressed as ratios between GSK3 $\beta$ and GAPDH mRNA levels relative to those in the same organs from Ctrl mice; ${ }^{*} P<0.01$ versus Ctrl kidney $(n=6)$. (d) The GSK3 $\beta$ gene was largely deleted by Cre-mediated excision only in the kidney of KO mice (genotype: $\mathrm{fl} / \mathrm{fl}$, Cre), but was barely affected either in other extrarenal organs, such as the heart of the KO mice or in any organs of Ctrl mice (genotype: $+/+$, Cre; or $\mathrm{fl} / \mathrm{fl})$. PCR analysis of exon 2 of the GSK3 $\beta$ gene and the Cre gene was carried out on genomic DNA extracted from the kidney or other extrarenal organs, such as the heart. The PCR bands of wild-type (886 bp) and floxed (1095 bp) GSK3 $\beta$ allele and excised (209 bp) fragment, and Cre (411 bp) allele are indicated. (e) Protein expression of GSK3 $\beta$ was successfully ablated only in the kidney of KO mice (genotype: fl/fl, Cre), but was affected neither in other extrarenal organs, such as the heart of the $\mathrm{KO}$ mice, nor in any organs of littermate controls (genotype: $+/+, \mathrm{Cre}$; or $\mathrm{fl} / \mathrm{fl}$; or $\mathrm{fl} /+$, cre). As control, renal expression of GSK3 $\beta$ was barely affected in KO mice, denoting a highly isoform-specific targeting of GSK3 in the kidney. (f) The temporally controlled inactivation of renal expression of GSK3 $\beta$ was associated with regulated expression of $\gamma$ GT and Cre. Immunoblot analysis of GSK3 $\beta$, $\gamma \mathrm{GT}, \mathrm{Cre}$, and actin was carried out on kidney homogenates derived from $\mathrm{KO}$ (genotype: $\mathrm{fl} / \mathrm{fl}, \mathrm{Cre}$ ) or Ctrl (genotype: fl/fl) mice. To confirm the specificity of the monoclonal anti-GSK3 $\beta$ antibody used to probe the blot, a recombinant standard GSK3 $\beta$ was loaded and analyzed simultaneously. Std.: recombinant standard GSK3 $\beta$. (g) Ablation of GSK3 $\beta$ was restricted to renal tubules. Kidney cryosections derived from KO or Ctrl mice were subjected to fluorescent immunohistochemistry staining of GSK3 $\beta$ (red color) by applying the monoclonal anti-GSK3 $\beta$ antibody used in panel $\mathbf{f}$ and counterstained with 4',6-diamidino-2-phenylindole (DAPI, blue color). White dotted lines highlight glomeruli. Scale bar $=20 \mu \mathrm{m}$. 
Under basal conditions, GSK3 $\beta$ is constitutively expressed in adult mice in different organs, including the kidney, heart (Figure 2e), skeletal muscle, and liver (data not shown). Inactivation of the GSK3 $\beta$ gene by Cre-mediated excision resulted in a reduction of the expression of the GSK3 $\beta$ protein only in the kidneys from KO mice. Western blot analysis demonstrated that expression level of the GSK $3 \beta$ protein in the kidneys was drastically reduced in $\mathrm{KO}$ mice, compared with controls (Figure 2e). No change in GSK3 $\beta$ protein expression was noted in other organs from $\mathrm{KO}$ mice or in any organs from control littermates. In contrast to diminished GSK3 $\beta$ expression in the kidneys from KO mice, expression of the GSK $3 \alpha$ isoform was barely affected, confirming a highly isoform-specific and spatially restricted gene targeting (Figure 2e).

As the expression of Cre recombinase was under the control of the $\gamma G T$ promoter, which becomes active in the kidney cortical tubular epithelium only in late kidney development stage, beginning around postpartum day 14 when nephrogenesis is virtually complete. ${ }^{28,32}$ To discern the temporally controlled ablation of GSK3 $\beta$ mediated by Cre in the kidney from KO mice, a time course examination of GSK3 $\beta$ expression in the KO kidney was carried out. As shown in Figure $2 \mathrm{f}, \gamma \mathrm{GT}$ was barely detected in both $\mathrm{KO}$ and Ctrl kidneys before 4 weeks after birth but was evidently induced and persistently expressed thereafter. Congruent with this, $\mathrm{KO}$ mice started to express Cre in the kidney after 4 weeks of age. Reciprocally, GSK3 $\beta$ was constitutively expressed in the kidney in the first 2 postpartum weeks but was later progressively and rapidly ablated, in agreement with $\gamma$ GTdependent Cre expression and Cre-mediated excision of the GSK3 $\beta$ gene (Figure 2f). In contrast, in the kidneys from control littermates (Ctrl), Cre expression was constantly absent and no significant changes to GSK3 $\beta$ expression were noted (Figure 2f). Furthermore, immunofluorescent staining demonstrated that GSK3 $\beta$ was basally and ubiquitously expressed in the glomeruli and tubules in kidney tissues from control littermates (Figure 2g). By contrast, in KO mice, a nearly complete elimination of GSK3 $\beta$ expression was observed in tubules, whereas glomerular expression was barely affected, denoting a tubular-specific knockout of GSK3 $\beta$ (Figure $2 \mathrm{~g}$ ). To confirm the specificity of the monoclonal antibody used for fluorescent immunohistochemistry staining, immunoblots of kidney homogenates probed by this antibody displayed a highly specific single target band of GSK $3 \beta$ as identified by a standard control of recombinant GSK3 $\beta$ (Figure $2 \mathrm{f}$ ).

\section{Renal Physiology of Adult Mice with Kidney-Specific Ablation of GSK3 $\beta$}

To estimate renal physiology, various kidney functional and biochemical parameters were assessed. As shown in Figure 3, $\mathrm{KO}$ mice and control littermates had equal serum creatinine levels (Figure 3a) and BUN levels (Figure 3b), implying that a

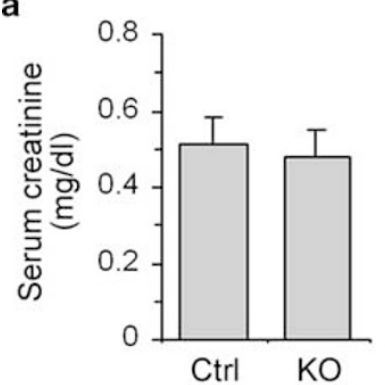

e

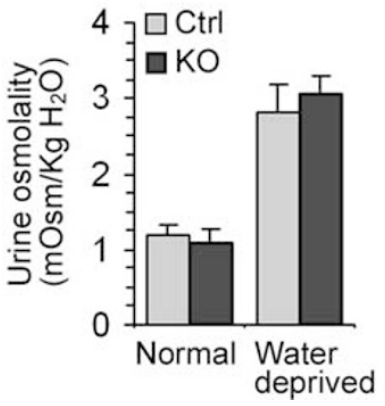

b

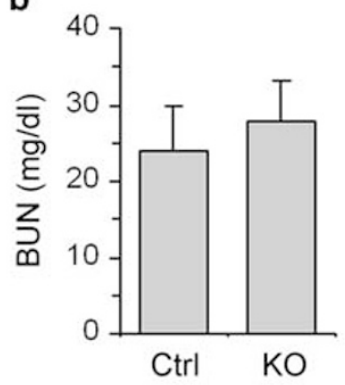

f

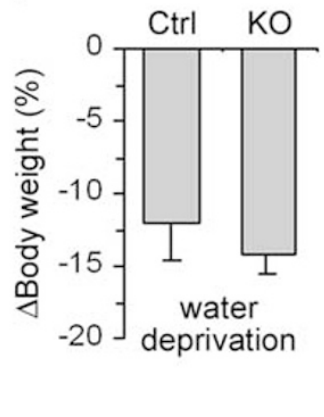

C

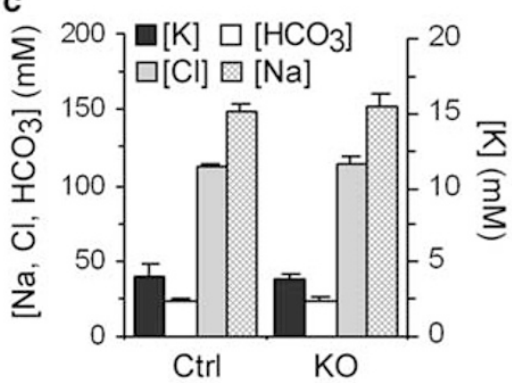

g

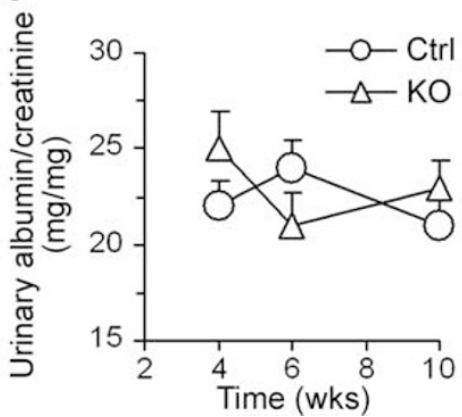

d

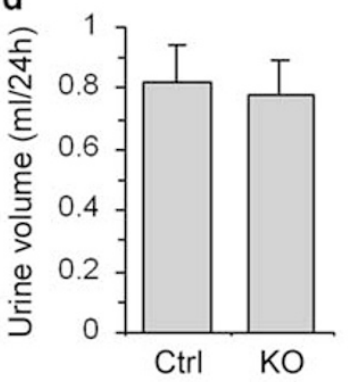

h

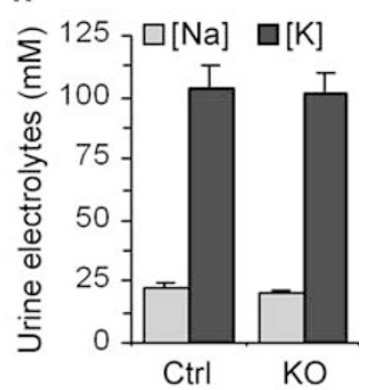

Figure 3 Kidney-specific conditional knockout of GSK3 $\beta$ in mice does not affect renal physiological function. Ten-week old mice were kept in metabolic cages and urine and blood samples were collected. Biochemistry analyses were carried out to determine (a) serum creatinine levels, (b) blood urea nitrogen levels, (c) serum potassium, sodium, chloride, and bicarbonate levels, (d) $24 \mathrm{~h}$ urine volume, (g) urinary albumin to creatinine ratios, (h) urinary sodium and potassium levels; besides, animals were subjected to water deprivation for $24 \mathrm{~h}$, followed by (e) urine osmolality assay and (f) measurement of body weight loss; KO versus Ctrl not significant $(n=6)$. 
mice had normal kidney function after kidney-specific GSK3 $\beta$ knockout. Analysis of serum electrolytes revealed similar levels of sodium, potassium, chloride, and bicarbonate in $\mathrm{KO}$ and control mice (Figure $3 \mathrm{c}$ ), excluding the possibility that GSK3 $\beta$ knockout induces tubular dysfunction and causes renal tubular acidosis. This is further supported by normal and comparable urine volume (Figure 3d), urine albumin to creatinine ratio (Figure $3 \mathrm{~g}$ ), and urinary sodium and potassium concentrations (Figure $3 \mathrm{~h}$ ) observed from the $\mathrm{KO}$ and Ctrl groups. In addition, urinary dipsticks were applied and demonstrated that urine samples from Ctrl and $\mathrm{KO}$ mice had comparable and normal $\mathrm{pH}(\sim 6)$ and were negative for glucose. Upon water restriction for $24 \mathrm{~h}, \mathrm{KO}$ mice and control littermates had comparable urine osmolality measured before or after water restriction (Figure 3e), as well as similar body weight loss (Figure $3 \mathrm{f}$ ), suggesting a normal tubular function after GSK3 $\beta$ inactivation. Moreover, MAP was measured before mice were killed and the MAP was $78.7 \pm 8.1 \mathrm{~mm} \mathrm{Hg}$ for control littermates and $81.7 \pm 7.6 \mathrm{~mm} \mathrm{Hg}$ for $\mathrm{KO}$ mice $(n=6 ; P=0.52)$, denoting that $\mathrm{KO}$ and Ctrl mice had comparable blood pressure. Collectively, these data suggest that postnatal knockout of GSK3 $\beta$ in the kidney does not affect renal physiological function under normal conditions.

\section{Renal Histology of Mice with Kidney-Specific Ablation of GSK3 $\beta$}

Under normal conditions, $\mathrm{KO}$ mice and control littermates excreted equal and scarce amounts of low-molecular-weight proteins in urine, which are consistent with small-sized proteins normally secreted by the tubular epithelium; no albumin or higher-molecular-weight proteins were observed in both control and $\mathrm{KO}$ mice at different ages as indicated (Figure $4 \mathrm{a}$ ), suggesting that $\mathrm{KO}$ mice are less likely to have glomerular sieving defect. In support of this, the kidneys from $\mathrm{KO}$ mice showed a normal glomerular morphology under H\&E staining (Figure $4 \mathrm{~b}$ ). This was further corroborated by immunofluorescent microscopic observations of equal expression and normal distribution of major slit diaphragm-associated proteins, including nephrin, podocin, and the podocyte-specific differentiation marker, WT1, in the glomeruli of the kidney from $\mathrm{KO}$ as compared with control littermates (Figure $4 \mathrm{~b}$ ). Fluorescent microscopic observations were revalidated by computerized morphometric analysis, again showing comparable staining intensity of various podocyte markers in the kidneys from both $\mathrm{KO}$ and control mice (Figure 4c). Immunoblot analysis of the glomeruli isolated from $\mathrm{KO}$ and Ctrl mice confirmed the morphology findings and showed equal expression of podocin, nephrin, and WT1 as referred to actin (Figure 4d). Moreover, electron microscopy demonstrated a normal glomerular morphology with an intact and normal ultrastructure of podocyte foot processes, slit diaphragms, glomerular base membrane, and glomerular capillary and mesangial area (Figure 4e).
The kidneys from KO mice also showed normal tubulointerstitium and vasculatures under $\mathrm{H} \& \mathrm{E}$ staining as compared with those from control littermates (Figure 5a). It is noteworthy that tubules in the KO kidneys demonstrated more intense PAS staining than did those from the Ctrl kidneys, mainly located in the brush border of the tubules (Figure 5a), denoting an elevated glycogen synthetic activity in the KO kidney. In consistence with this finding, immunoblot analysis of kidney homogenates indicated that inhibitory phosphorylation of glycogen synthase was substantially diminished, subsequent to GSK3 $\beta$ ablation in the KO kidneys (Figure 5b). Furthermore, biochemical quantification of glycogen with an acid hydrolysis technique applied to fresh kidney samples independently demonstrated significantly more glycogen content in the KO kidney (Figure 5c), confirming the morphology findings on PAS staining. Electron microscopy reveals normal morphology and quantity of subcellular organelles, including the nucleus, mitochondria, endoplasmic reticulum, and Golgi complex in proximal tubules. Notably, compared with the control group (Figure 6A, $\mathrm{A}^{\prime}$ ), tubules in the KO kidney (Figure 6B, $\mathrm{B}^{\prime}$ ) contained prominently more glycogen particles under ultrastructural analysis, which appeared as electron-dense particles ranging in size from 20 to $25 \mathrm{~nm}$ in diameter and closely associated with tubules of the smooth endoplasmic reticulum. Absolute counting of glycogen particles corroborated the electron microscopic observations and showed that the amount of total measurable glycogen was markedly increased in $\mathrm{KO}$ mice.

\section{DISCUSSION}

GSK3 is a ubiquitously expressed serine/threonine kinase encoded by two isoforms, namely GSK $3 \alpha$ and GSK $3 \beta$. In cell signaling networks, GSK3 resides at the nexus of multiple pathways, including insulin signaling pathway, canonical wingless (Wnt) pathway, ${ }^{33} \mathrm{NF} \kappa \mathrm{B},{ }^{13-15,24}$ and NF-AT ${ }^{3}$ pathway. Besides glycogen synthase, GSK3 has been shown to phosphorylate a number of other substrates, such as the microtubule-associated protein tau, adenomatous polyposis coli, and various transcription factors, including $\beta$-catenin, NF-AT, NF $\kappa$ B, c-Myc, c-Jun, and c-Myb., ${ }^{2,3}$ Initially identified as a regulator of glycogen biosynthesis, GSK3 is now known to be a key regulator of a large number of cellular processes and has been implicated in diverse diseases including diabetes, Alzheimer's disease, stroke, and inflammatory diseases. ${ }^{19,20,25,34}$

In the kidney, expression of GSK3 $\beta$ is low under physiological conditions, but is prominently induced in the tubular epithelia upon disease state, including lupus nephritis, acute cellular rejection of the allograft kidney, and chronic renal allograft disease. ${ }^{16,18}$ Although the increased GSK3 $\beta$ expression was found to highly correlate with the extent of kidney injury, ${ }^{16}$ whether this elevated expression of GSK $3 \beta$ is a selfprotective mechanism or an event that mediates kidney injury is largely unknown. To address this issue, recent studies 
a
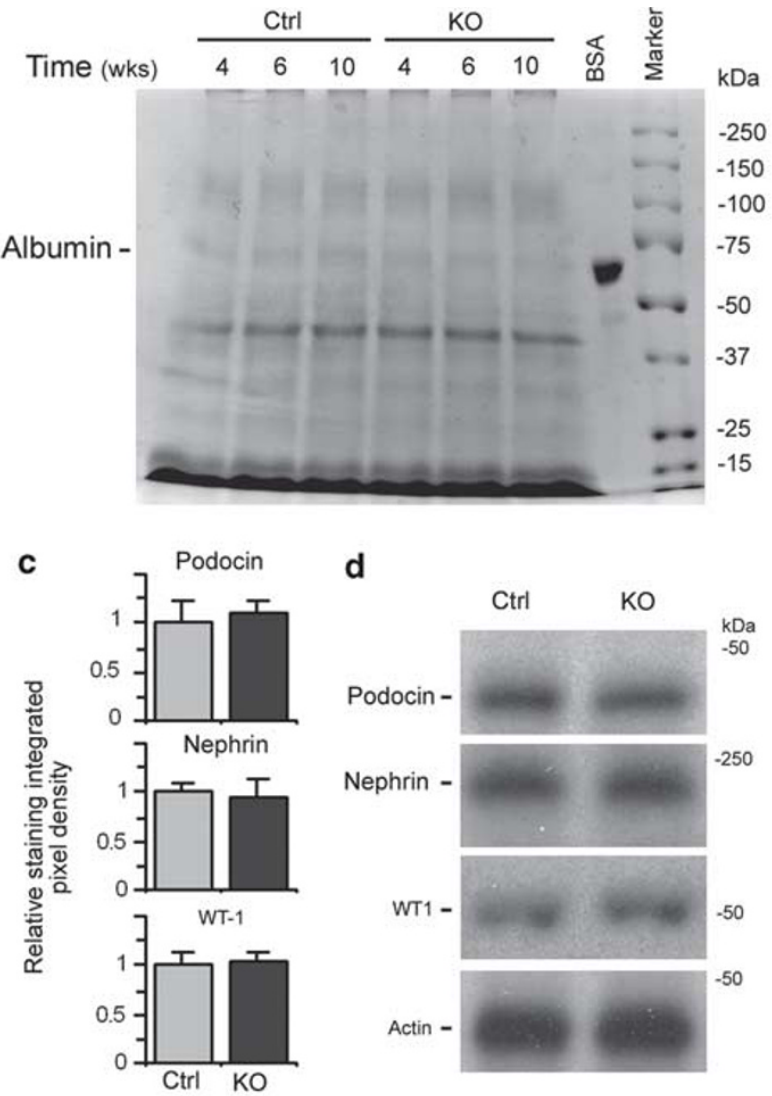

d
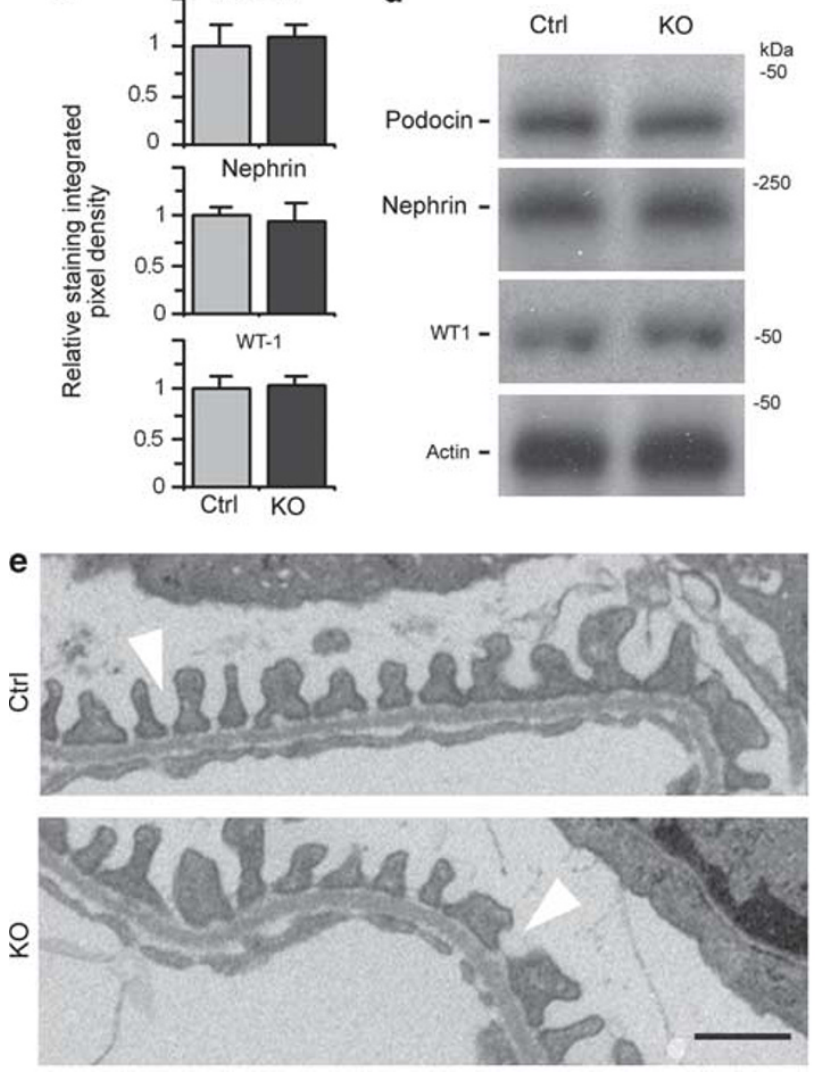

b
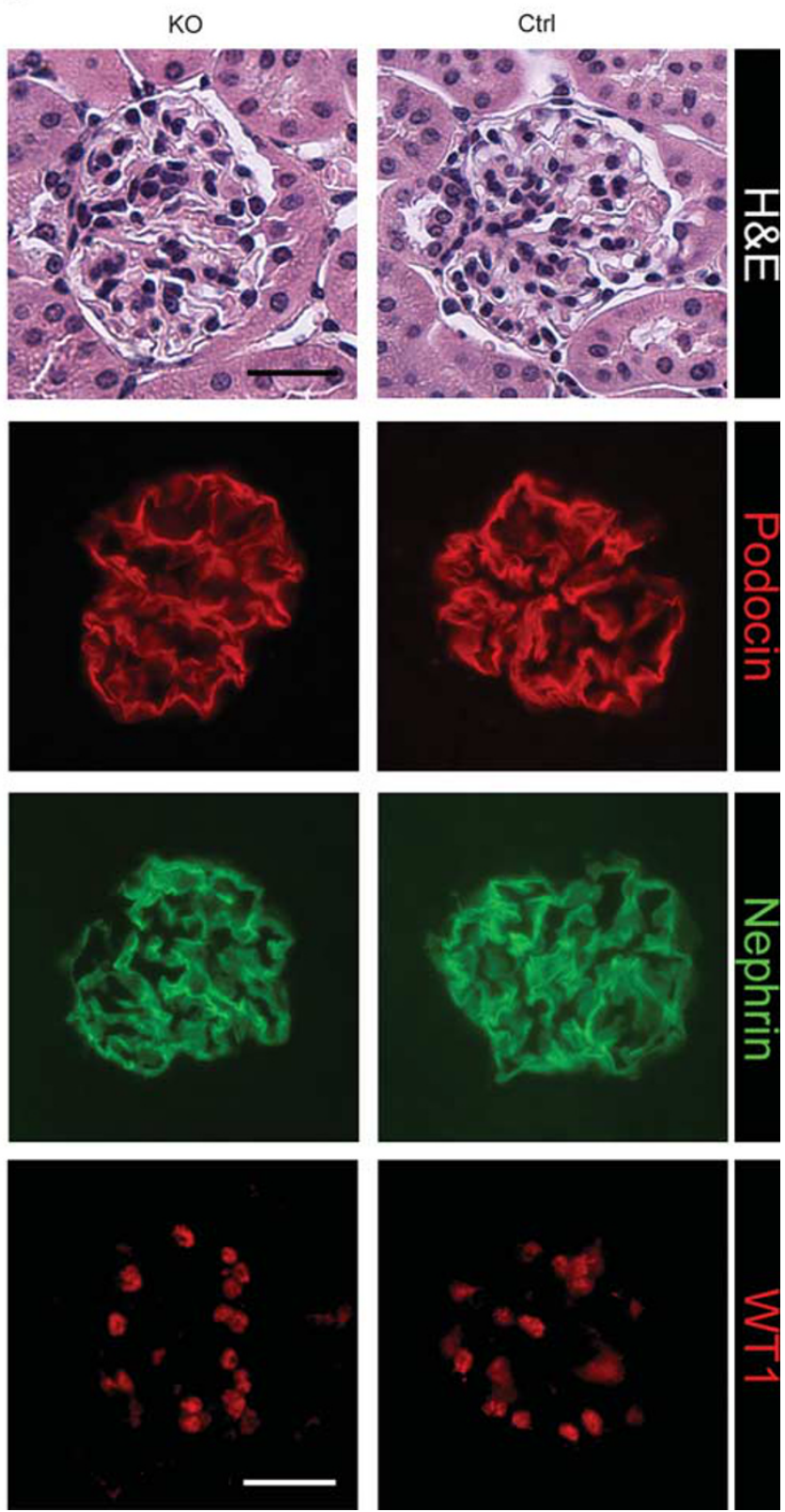

Figure 4 Ablation of GSK3 $\beta$ in kidney tubules does not affect normal glomerular morphology or podocyte structure. (a) Representative SDS-PAGE, followed by Coomassie blue staining shows urine protein compositions in $\mathrm{KO}$ or Ctrl mice at different ages as indicated. BSA, bovine serum albumin. (b) Knockout mice (KO) and control littermates (Ctrl) have comparable glomerular morphology under H\&E staining for light microscopy and normal distribution and equal expression intensity of podocyte slit diaphragm proteins such as podocin and nephrin and the podocyte-specific differentiation marker WT1 under immunofluorescent microscopy. Scale bar $=20 \mu \mathrm{m}$. (c) Computerized morphometric analysis of fluorescent immunohistochemistry staining shows integrated pixel density of podocin, nephrin, and WT1 in the glomeruli in KO mice relative to that in Ctrl mice; KO versus Ctrl not significant ( $n=6$ ). (d) Immunoblot analysis of the glomeruli isolated from KO and Ctrl mice shows equal expression of podocin, nephrin, WT1, and actin. (e) Electron microscopy reveals normal and comparable podocyte foot processes and slit diaphragms in KO mice and Ctrl littermates. Scale bar $=1 \mu \mathrm{m}$. Arrowheads indicate secondary foot processes of podocytes and slit diaphragms.

have used the highly selective small molecule inhibitors of GSK3. In rats with acute endotoxemia, specific GSK3 inhibitors suppressed $\mathrm{NF} \kappa \mathrm{B}$ activation, ameliorated systemic inflammatory responses, and reduced injury in multiple organs, including the kidney. ${ }^{23,35}$ Moreover, in mice stimulated with lipopolysaccharide, Martin et $a l^{21}$ demonstrated that GSK3 inhibition attenuated proinflammatory cytokines (IL-12, IL-6, and IFN- $\gamma$ ), enhanced production of the antiinflammatory cytokine IL-10, and improved kidney injury and general survival. ${ }^{22}$ All these findings suggest that GSK3 has a detrimental role in kidney injury and that the suppression of GSK3 is renoprotective. However, the effect of 
a
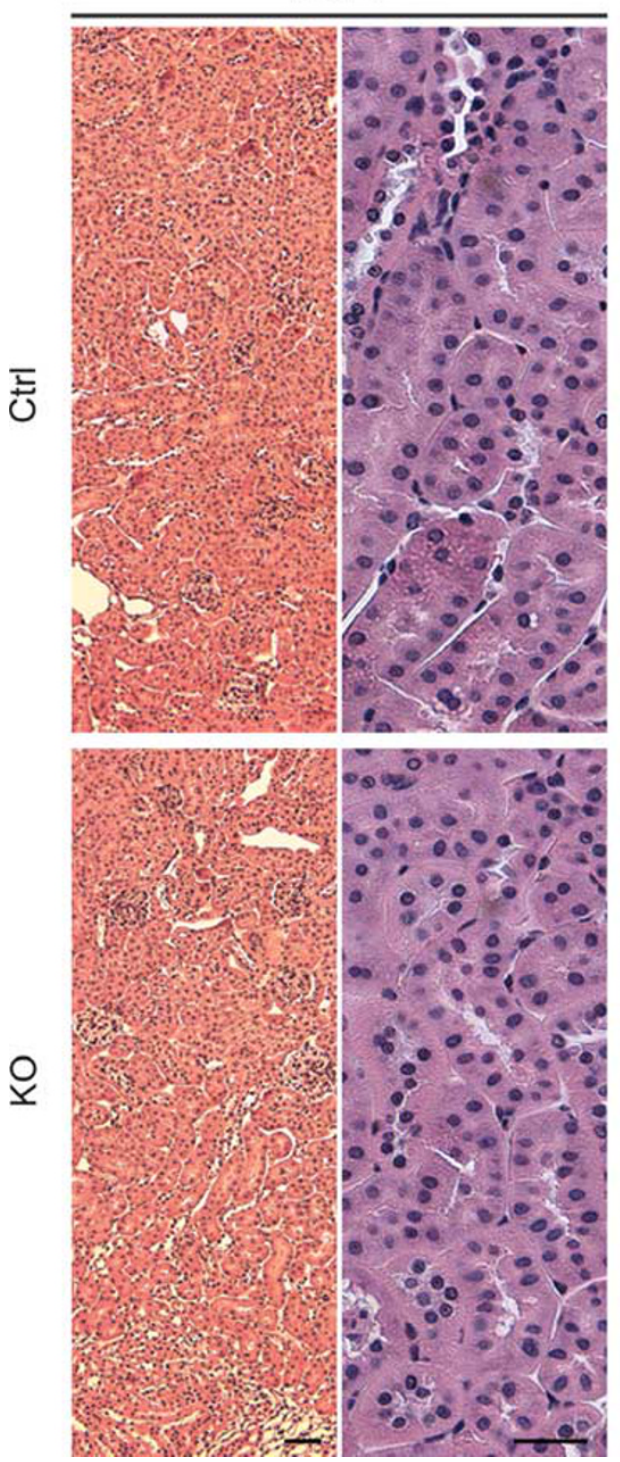

PAS
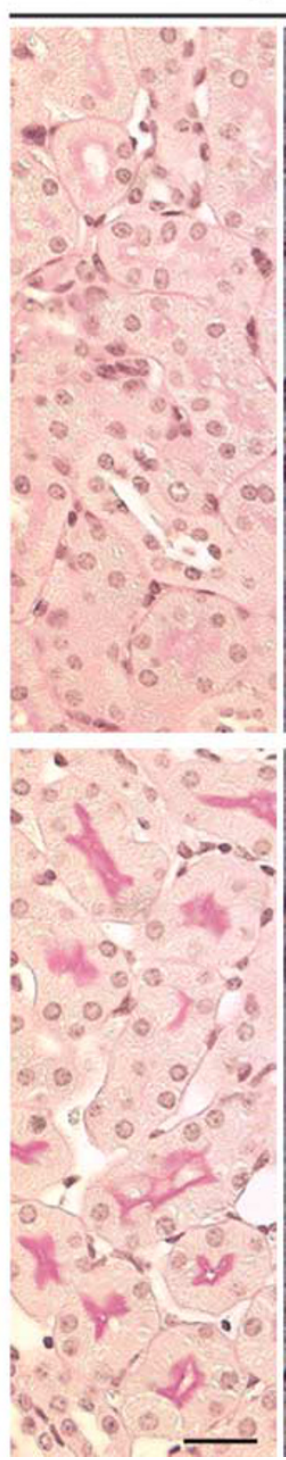

b
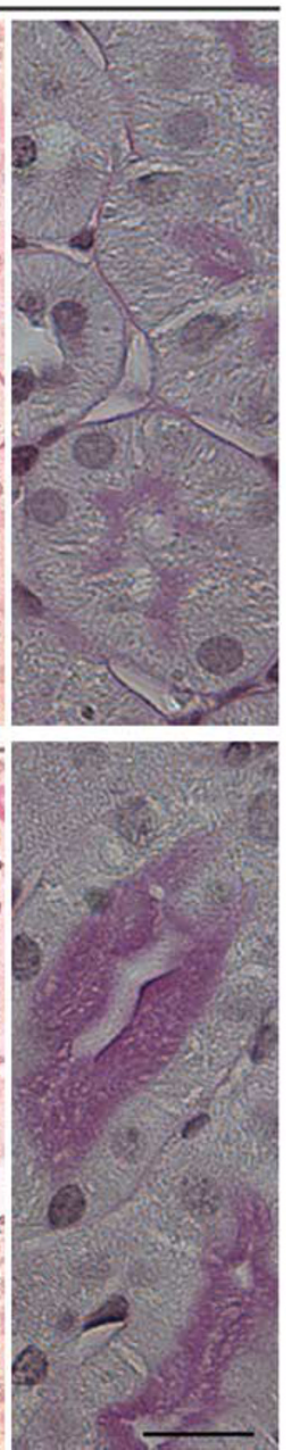
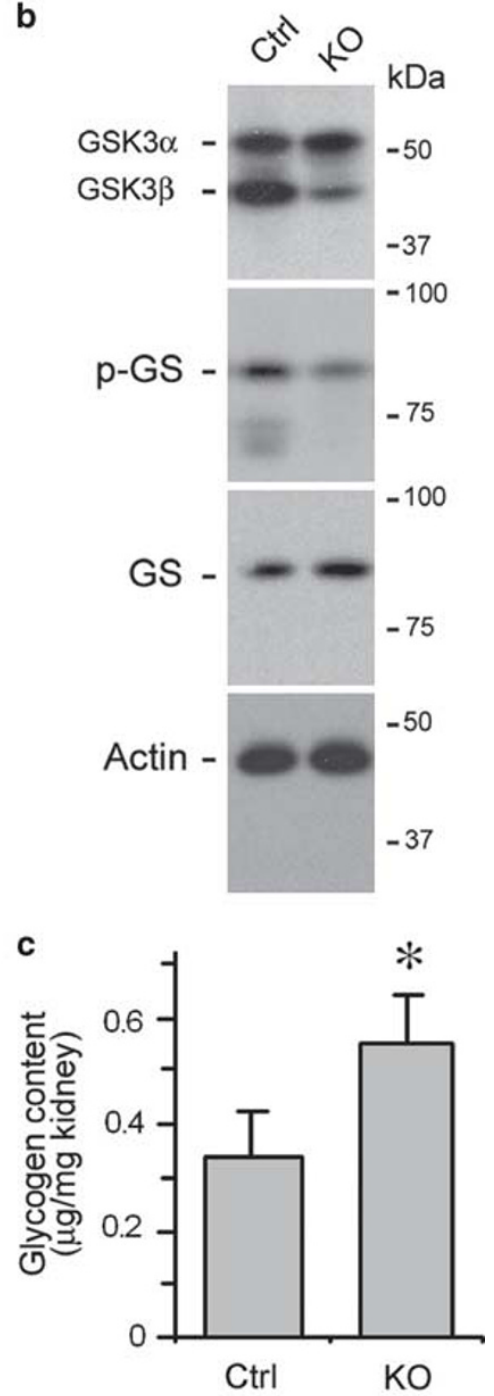

Figure 5 Kidney-specific GSK3 $\beta$ gene knockout results in more glycogen accumulation in tubules. (a) Under H\&E staining, knockout mice (KO) and control littermates (Ctrl) had normal and comparable morphology of renal tubulointerstitium, whereas under periodic acid-Schiff (PAS) staining, more intense glycogen staining was noted in the kidneys from KO mice, mainly located to the brush border of renal tubules. Scale bar $=20 \mu \mathrm{m}$. (b) Immunoblot analysis of kidney homogenates confirmed that GSK3 $\beta$ expression was largely ablated, whereas GSK3 $\alpha$ was spared, and subsequently the inhibitory phosphorylation of glycogen synthase (GS) was diminished in the KO kidneys. (c) Biochemistry assay of glycogen content in the kidney tissue reveals more glycogen accumulation in the KO group; ${ }^{\star} P<0.05$ versus $C$ trl group $(n=6)$.

administration of small molecule chemical compounds is not kidney specific but systemic, and might have a general protective effect as evidenced by the diminished levels of circulating cytokines in treated animals, ${ }^{21,22}$ which could have a secondary beneficial action on injuries to every organ systems, including the kidney. Therefore, whether induced GSK3 $\beta$ expression in the kidney mediates the injury and whether inhibition of GSK3 $\beta$ in the kidney is directly renoprotective still remains uncertain. In addition, a major pitfall of using these small molecule chemical compounds is that even the newly discovered novel inhibitors, which have been claimed to have very high selectivity on GSK3, actually still have some nonspecific inhibitory effects on other cell signaling transducers including the cyclin-dependent kinase, ${ }^{18}$ which also has a critical role in regulating cell cycles, inflammatory response, and immune reaction. Therefore, whether the renoprotective action is actually attributable to GSK3 $\beta$ inhibition or due to an unspecific effect on other signaling transducers is uncertain. Moreover, so far, no chemical inhibitors have been found to only inhibit GSK3 $\beta$ but barely affect GSK3 $\alpha{ }^{20,25}$ Thus, the arbitrary conclusion that renoprotection by these small molecule inhibitors is due to 

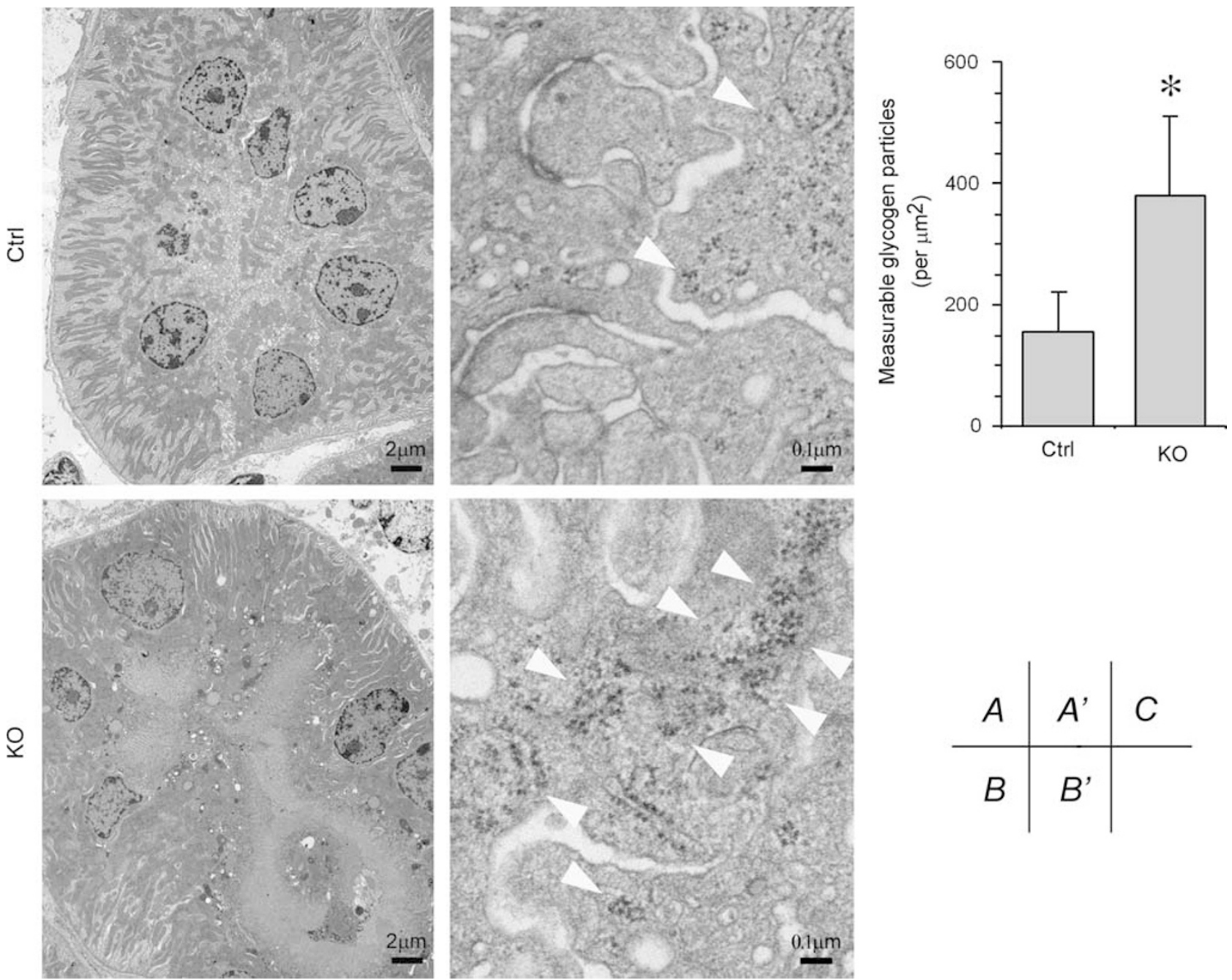

Figure 6 Ultrastructural analysis reveals increased deposition of glycogen particles in renal cortical tubules in mice with kidney-specific conditional knockout of the GSK3 $\beta$ gene. ( $\left.A, A^{\prime}, B, B^{\prime}\right)$ Kidney tissues from control littermates ( $C$ trl; $\left.A, A^{\prime}\right)$ and knockout mice $\left(K O\right.$; $\left.B, B^{\prime}\right)$ were prepared for transmission electron microscopy analysis. White arrowheads indicate glycogen particles, which appear as electron-dense particles ranging in size from 20 to $25 \mathrm{~nm}$ in diameter and closely associated with tubules of smooth endoplasmic reticulum. (C) Absolute counting of total measurable glycogen particles was performed; ${ }^{*} P<0.05$ versus $\mathrm{Ctrl}(n=6)$.

suppression of the activity of the $\beta$-isoform of GSK3 is doubtful and unwarranted, and the exact role of GSK3 $\beta$ in the pathogenesis of kidney disease is still obscure.

To address these unresolved issues, genetic knockout of GSK3 $\beta$ would be instrumental and highly selective. However, GSK3 $\beta$ is ubiquitously expressed and critical for embryonic development and traditional global knockout of GSK3 $\beta$ is lethal; mice die during the embryo stage because of severe hepatic necrosis and massive hepatocyte apoptosis, ${ }^{10}$ thus making it impossible to obtain adult animals to set up models of kidney disease for studying the effects of GSK3 $\beta$. Hence, a kidney-specific conditional knockout of GSK3 $\beta$ is imperative to decipher the role of GSK3 $\beta$ in kidney physiology and pathology. The Cre/loxP gene targeting system is a powerful and versatile tool for examining tissue-specific gene function in vivo that cannot be investigated by conventional knockout due to embryonic lethality. ${ }^{27}$ In the $\mathrm{Cre} /$ loxP system, genomic excision of the loxP-tagged gene is controlled by Cre recombinase and only occurs in Cre-expressing tissues. ${ }^{27}$ By far, multiple mouse strains have been created to express Cre exclusively in the kidney under the control of promoters of kidney-specific molecules. Unfortunately, most of these mice start to express Cre in kidney cells as early as in the embryo stage. ${ }^{27}$ As mentioned above, GSK $3 \beta$ is critically important for signaling pathways controlling embryo development, like the Wnt pathway, ${ }^{33}$ in many organ systems, including the kidney. ${ }^{26}$ Therefore, ablation of GSK3 $\beta$ using these Cre-expressing mice would possibly induce defects in embryo kidney development. The transgenic mice used in this study express Cre recombinase under the control of a $\gamma G T$ promoter and produce Cre recombinance only in the kidney cortical tubular epithelium, 
but not in other tissues, including the brain, liver, spleen, skeletal muscle, lung, bone marrow, or adrenal gland. ${ }^{28}$ Importantly, $\gamma G T$ promoter-governed Cre expression occurs in the late stage of kidney development, beginning around postpartum day 14 when nephrogenesis is virtually complete. ${ }^{28,32}$ Consistently, in our mice with GSK3 $\beta$ ablation, no notable defects were observed in the kidney either morphologically or functionally, suggesting that postnatal disruption of GSK3 $\beta$ is less likely to cause developmental abnormality. In addition, glomerular and tubulointerstitial histology reveals normal kidney structures in $\mathrm{KO}$ that are basically no different from control littermates. One potential limitation of our study is that GSK3 $\beta$ was ablated in only one portion of the renal epithelia and no other renal cell lineages were impacted and this might result in no renal phenotype. In-depth studies to knockout GSK3 $\beta$ in other nephron segments are merited to verify our observations and to define the exact role of GSK3 $\beta$ in nephrobiology.

The current understanding of the impact of GSK3 $\beta$ inhibition in vivo on kidney physiology are mainly based on the studies of lithium, an antipsychotic and antimanic drug ${ }^{36}$ that has been lately demonstrated to have potent GSK3 inhibitory activity. ${ }^{37,38}$ Lithium has been widely used as a mood stabilizer for decades in patients with psychiatric diseases, including mania, depression, and bipolar affective disorder. ${ }^{36}$ Side effects have been occasionally reported, including vasopressin-resistant nephrogenic diabetes insipidus, increased urinary sodium loss, and renal tubular acidosis. ${ }^{36,39-42}$ Moreover, chronic lithium treatment is associated with chronic interstitial nephritis and a major cellular reorganization of the collecting duct cells with a marked increase in the fraction of intercalated cells and a significant decrease in the fraction of principal cells. ${ }^{41,42}$ However, these findings might be flawed because healthy subjects were used as controls and chronic renal lesions were also found in psychiatric patients not treated with lithium, suggesting that chronic interstitial nephritis may be associated with psychiatric disorders per se and not with lithium treatment. ${ }^{39,40}$ Nevertheless, lesions such as cytoplasmic swelling with dilated tubules and glycogen accumulation in renal tubules have been consistently noted in lithium-treated patients but not found in psychiatric controls. ${ }^{41,43}$ Despite these longrecognized side effects of lithium on renal physiology, the molecular mechanisms and responsible drug targets remain highly illusive. One explanation is that lithium may obliterate cyclic adenosine monophosphate signaling pathways that are important in the maintenance of kidney architecture and physiological homeostasis, such as regulation of water balance. ${ }^{41,42}$ Besides, recently, lithium has been postulated to induce renal physiology changes by GSK3 inhibition. ${ }^{37-39}$ However, owing to the drawbacks of the poor selectivity of lithium, inhibition of which GSK3 isoform accounts for the renal effects is not clear, and conditional $\mathrm{KO}$ generated in this study will be instrumental in deciphering this issue. As a matter of fact, although kidney-specific GSK3 $\beta$ KO did not show any notable difference from littermate controls in terms of kidney function, proteinuria, urine-concentrating ability, as well as glomerular and tubulointerstital histology, more glycogen deposition was found in the tubules as evidenced by PAS staining and under ultrastructure examination as well, congruent with the findings in lithium-treated patients. ${ }^{40,43}$ Accordingly, extended observations of these mice under normal or diseased conditions are warranted to understand the role of GSK3 $\beta$ in lithium-induced histological and functional changes of the kidney.

In conclusion, we have successfully established a conditional knockout mouse model with kidney-specific ablation of GSK3 $\beta$ at postnatal mature stage. The mice had a phenotype no different from control littermates, except they had more glycogen accumulation in renal cortical tubules, supporting that GSK3 $\alpha$ could not fully compensate for the loss of GSK $3 \beta$ in this regard. Our findings provide new insights into the functional role of GSK $3 \beta$ in kidney biology and in the maintenance of kidney homeostasis. This transgenic mouse model would be instrumental in deciphering the exact role of GSK3 $\beta$ in kidney physiology and pathology.

\section{ACKNOWLEDGEMENTS}

We are grateful to Drs Woodgett and Neilson for generously providing transgenic mice. This study was supported by the Rhode Island Medical Foundation, the Lifespan Developmental Grant, the Young Investigator Research Award from the Foundation for Health, and the intramural research funds from the Departmental of Medicine of Brown Medical School (to RG).

\section{DISCLOSURE/CONFLICT OF INTEREST}

The authors declare no conflict of interest.

1. Ali A, Hoeflich KP, Woodgett JR. Glycogen synthase kinase-3: properties, functions, and regulation. Chem Rev 2001;101:2527-2540.

2. Cohen P, Frame S. The renaissance of GSK3. Nat Rev Mol Cell Biol 2001:2:769-776.

3. Doble BW, Woodgett JR. GSK-3: tricks of the trade for a multi-tasking kinase. J Cell Sci 2003;116:1175-1186.

4. Frame S, Cohen P. GSK3 takes centre stage more than 20 years after its discovery. Biochem J 2001;359:1-16.

5. Rayasam GV, Tulasi VK, Sodhi R, et al. Glycogen synthase kinase 3: more than a namesake. Br J Pharmacol 2009;156:885-898.

6. Jope RS, Johnson GV. The glamour and gloom of glycogen synthase kinase-3. Trends Biochem Sci 2004;29:95-102.

7. Lee HC, Tsai JN, Liao PY, et al. Glycogen synthase kinase 3 alpha and 3 beta have distinct functions during cardiogenesis of zebrafish embryo. BMC Dev Biol 2007;7:93.

8. Patel S, Doble BW, MacAulay K, et al. Tissue-specific role of glycogen synthase kinase 3beta in glucose homeostasis and insulin action. Mol Cell Biol 2008;28:6314-6328.

9. Van Wauwe J, Haefner B. Glycogen synthase kinase-3 as drug target: from wallflower to center of attention. Drug News Perspect 2003;16:557-565.

10. Hoeflich KP, Luo J, Rubie EA, et al. Requirement for glycogen synthase kinase-3beta in cell survival and NF-kappaB activation. Nature 2000;406:86-90.

11. Haefner B. A model for NF-kappa B regulation by GSK-3 beta. Drug Discov Today 2003;8:1062-1063.

12. Pomerantz JL, Baltimore D. Signal transduction. A cellular rescue team. Nature 2000:406:26-27, 29.

13. Schwabe RF, Brenner DA. Role of glycogen synthase kinase-3 in TNF-alpha-induced NF-kappaB activation and apoptosis in hepatocytes. Am J Physiol Gastrointest Liver Physiol 2002;283:G204-G211. 
14. Gong R, Rifai A, Ge $Y$, et al. Hepatocyte growth factor suppresses proinflammatory NFkappaB activation through GSK3beta inactivation in renal tubular epithelial cells. J Biol Chem 2008;283:7401-7410.

15. Steinbrecher KA, Wilson III W, Cogswell PC, et al. Glycogen synthase kinase 3beta functions to specify gene-specific, NF-kappaB-dependent transcription. Mol Cell Biol 2005;25:8444-8455.

16. Gong R, Ge Y, Chen S, et al. Glycogen synthase kinase 3beta: a novel marker and modulator of inflammatory injury in chronic renal allograft disease. Am J Transplant 2008;8:1852-1863.

17. Gong R, Rifai A, Dworkin LD. Activation of PI3K-Akt-GSK3beta pathway mediates hepatocyte growth factor inhibition of RANTES expression in renal tubular epithelial cells. Biochem Biophys Res Commun 2005;330:27-33.

18. Obligado SH, Ibraghimov-Beskrovnaya O, Zuk A, et al. CDK/GSK-3 inhibitors as therapeutic agents for parenchymal renal diseases. Kidney Int 2008;73:684-690.

19. Martinez A, Castro A, Dorronsoro l, et al. Glycogen synthase kinase 3 (GSK-3) inhibitors as new promising drugs for diabetes, neurodegeneration, cancer, and inflammation. Med Res Rev 2002;22: 373-384.

20. Hernandez F, Nido JD, Avila J, et al. GSK3 inhibitors and disease. Mini Rev Med Chem 2009;9:1024-1029.

21. Martin M, Rehani K, Jope RS, et al. Toll-like receptor-mediated cytokine production is differentially regulated by glycogen synthase kinase 3 . Nat Immunol 2005;6:777-784.

22. Woodgett JR, Ohashi PS. GSK3: an in-Toll-erant protein kinase? Nat Immunol 2005;6:751-752.

23. Dugo $L$, Collin M, Thiemermann C. Glycogen synthase kinase 3beta as a target for the therapy of shock and inflammation. Shock 2007;27:113-123.

24. Demarchi F, Bertoli C, Sandy P, et al. Glycogen synthase kinase-3 beta regulates NF-kappa B1/p105 stability. J Biol Chem 2003;278: 39583-39590.

25. Cohen P, Goedert M. GSK3 inhibitors: development and therapeutic potential. Nat Rev Drug Discov 2004;3:479-487.

26. Kuure $S$, Popsueva $A$, Jakobson $M$, et al. Glycogen synthase kinase-3 inactivation and stabilization of beta-catenin induce nephron differentiation in isolated mouse and rat kidney mesenchymes. J Am Soc Nephrol 2007;18:1130-1139.

27. Igarashi P. Kidney-specific gene targeting. J Am Soc Nephrol 2004;15:2237-2239.
28. Iwano $M$, Plieth $D$, Danoff $T M$, et al. Evidence that fibroblasts derive from epithelium during tissue fibrosis. J Clin Invest 2002;110: 341-350.

29. Chen S, Ge Y, Si J, et al. Candesartan suppresses chronic renal inflammation by a novel antioxidant action independent of AT1R blockade. Kidney Int 2008;74:1128-1138.

30. Gong R, Rifai A, Dworkin LD. Anti-inflammatory effect of hepatocyte growth factor in chronic kidney disease: targeting the inflamed vascular endothelium. J Am Soc Nephrol 2006;17:2464-2473.

31. Takemoto $M$, Asker N, Gerhardt $H$, et al. A new method for large scale isolation of kidney glomeruli from mice. Am J Pathol 2002;161: 799-805.

32. Gomez RA, Sequeira Lopez ML, Fernandez $L$, et al. The maturing kidney: development and susceptibility. Ren Fail 1999;21:283-291.

33. Wu D, Pan W. GSK3: a multifaceted kinase in Wnt signaling. Trends Biochem Sci 2010;35:161-168.

34. Yuskaitis CJ, Jope RS. Glycogen synthase kinase-3 regulates microglial migration, inflammation, and inflammation-induced neurotoxicity. Cell Signal 2009;21:264-273.

35. Dugo L, Collin M, Allen DA, et al. GSK-3beta inhibitors attenuate the organ injury/dysfunction caused by endotoxemia in the rat. Crit Care Med 2005;33:1903-1912.

36. Coryell W. Maintenance treatment in bipolar disorder: a reassessment of lithium as the first choice. Bipolar Disord 2009;11(Suppl 2):77-83.

37. O'Brien WT, Klein PS. Validating GSK3 as an in vivo target of lithium action. Biochem Soc Trans 2009;37:1133-1138.

38. De Sarno P, Li X, Jope RS. Regulation of Akt and glycogen synthase kinase-3 beta phosphorylation by sodium valproate and lithium Neuropharmacology 2002;43:1158-1164.

39. Gitlin M. Lithium and the kidney: an updated review. Drug Saf 1999;20:231-243.

40. Hetmar O, Brun C, Ladefoged J, et al. Long-term effects of lithium on the kidney: functional-morphological correlations. J Psychiatr Res 1989;23:285-297.

41. Timmer RT, Sands JM. Lithium intoxication. J Am Soc Nephrol 1999;10:666-674.

42. Smith GC, Balfe JW, Kooh SW. Anticonvulsants as a cause of Fancon syndrome. Nephrol Dial Transplant 1995;10:543-545.

43. Jorgensen F, Larsen S, Spanager B, et al. Kidney function and quantitative histological changes in patients on long-term lithium therapy. Acta Psychiatr Scand 1984;70:455-462. 